\title{
La embargabilidad de los bienes patrimoniales de las Administraciones Públicas. Comentario a la Sentencia del Tribunal Constitucional 166/1998, de 15 de julio *
}

\author{
José Vicente Morote Sarrión \\ Profesor Ayudante de Derecho Administrativo
}

Sumario: 1. EMBARGABILIDAD DE LOS BIENES PATRIMONIALES DE LOS ENTES LOCALES. 2. ANTECEDENTES JURISPRUDENCIALES. 3. INNOVADORA DOCTRINA DE LA SENTENCIA. EMBARGABILIDAD DE LOS BIENES PATRIMONIALES NO AFECTOS A UN USO O SERVICIO PÚBLICO. 4. REFLEXIONES AL HILO DE LA SENTENCIA. 4.1. Influencia del sistema italiano. La separación entre patrimonio disponible y patrimonio indisponible. 4.2. Extensión de los efectos de la Sentencia al resto de las Administraciones públicas territoriales. 4.3. Situación del resto de los preceptos que consagran la inembargabilidad de los bienes patrimoniales de la Administración. 4.4. Consideraciones finales.

\section{EMBARGABILIDAD DE LOS BIENES PATRIMONIALES DE LOS ENTES LOCALES}

Nuestro ordenamiento jurídico ha recogido tradicionalmente la regla de la inembargabilidad de los bienes de las Administraciones Públicas en diferentes preceptos, tanto para los patrimoniales como para los de dominio público ${ }^{1}$. Este principio venía establecido en atención a criterios subjetivos y no funcionales, ya que todos los bienes de la Administración se entendían como inembargables con independencia de su naturaleza y de cuál fuera el destino que se les diera.

La Constitución de 1978, al otorgar un tratamiento claramente diferenciado a ambos tipos de bienes en el artículo 132, estableciendo mayor protección para los bienes de dominio público, abre el camino que esta sentencia

\footnotetext{
* Este artículo se terminó de elaborar el 10 de enero de 1999, por lo que no se recogen ni las aportaciones doctrinales ni jurisprudenciales aparecidas con posterioridad.

' En los articulos 91 y 96 de la Ley de Ayuntamientos, de 8 de enero de 1845, se establecia la inclusión en los presupuestos municipales como gastos obligatorios los pagos de deudas. La Real Orden de 21 de enero de 1845 ordenaba la suspensión inmediata de toda ejecución y apremio contra fondos municipales. En esa misma línea la Circular del Ministerio de la Gobernación de 19 de mayo de 1845 y la Real Orden de 22 de septiembre de 1845. De ahí pasará a la Ley de Bases de Contabilidad General, Provincial y Municipal, de 20 de febrero de 1850, y a la Ley Municipal de 1877 y de ahi llega hasta la legislación actual.
} 
continúa hasta afirmar la embargabilidad de parte de los bienes patrimoniales. La sentencia establece la posibilidad de embargar los bienes patrimoniales que no estén afectos materialmente a un uso o servicio público. Se gana sin duda con ello, ya que se mejora la seguridad del tráfico y se incrementan las garantías del recurrente que obtiene una sentencia de condena de cantidad líquida contra la Administración. Se supera consecuentemente, en parte, la situación de desprotección en que quedaba quien habiendo obtenido una sentencia de este tipo contra la Administración, veía cómo ésta no procedía al pago o si lo hacía era después de un largo período de tiempo, produciéndose una vulneración de los derechos del particular ${ }^{2}$. Se elimina, de esta manera, un privilegio injustificado de la Administración.

Coincide, en el tiempo, esta STC de 15 de julio con la aprobación de la nueva de Ley de la Jurisdicción Contencioso-Administrativa de 13 de julio. Únicamente dos días separan la sentencia de la Ley. Ambas, además de en el tiempo, coinciden en la idea sobre el proceso de ejecución de sentencias ${ }^{3}$. Se produce, con estas dos disposiciones, una de carácter jurisprudencial y otra de carácter legislativo, la judicialización casi definitiva del proceso de ejecución de sentencias ${ }^{4}$. Por una parte, la nueva Ley de la Jurisdicción Contencioso-Administrativa, en su artículo $103^{5}$, da a los Tribunales la facultad de hacer ejecutar lo juzgado, sustituyendo al artículo 103 de la vieja Ley de la Jurisdicción que reservaba la ejecución de sentencias a la propia Administración ${ }^{6}$. Y por la otra, la STC amplía la

${ }^{2}$ Vid. Pablo González Mariñas, La inejecución de sentencias de los Tribunales Contencioso-Administrativos, ENAP, Madrid, 1975, p. 68, que habla de «una auténtica burla».

${ }^{3}$ Gimeno Sendra ponía ya de manifiesto en 1980 cómo la jurisdiccionalización del proceso de ejecución de sentencias debería llevar aparejada la remoción de un grave inconveniente, que debería ser revisado y ese obstáculo era la inembargabilidad de los bienes de la Administración Pública. José Vicente GIMENo SENDRA, «Alternativas a la disfuncionalidad del procedimiento de ejecución de sentencias contencioso-administrativas", en REDA, $\mathrm{n}^{\circ} 27$, octubre-diciembre 1980 , pp. 563-576.

${ }^{4}$ La ejecución por parte de la Administración de las sentencias judiciales es uno de los puntos de la antigua Ley de la Jurisdicción Contencioso-Administrativa que ha dado lugar a una mayor polémica, hasta tal punto que GarRIDo Falla lo entendía como el aspecto más criticable de la Ley. Vid. Fernando GARRIDO FALLA, «La evolución del recurso contencioso-administrativo en España», RAP, n. ${ }^{\circ} 55$, enero-abril, 1968, pp. 9-26 y en concreto 23.

${ }^{5}$ Artículo 103. «1. La potestad de hacer ejecutar las sentencias y demás resoluciones judiciales corresponde exclusivamente a los Juzgados y Tribunales de este orden jurisdiccional, y su ejercicio compete al que haya conocido del asunto en primera o única instancia.»

${ }^{6}$ Disponía el artículo 103 de la vieja Ley de la Jurisdicción Contencioso-Administrativa de 1956: «La ejecución de Sentencias corresponderá al órgano que hubiere dictado el acto o la disposición objeto del recurso.» Este precepto era de dudosa constitucionalidad después de la entrada en vigor de la Constitución de 1978 y en concreto de su artículo 117.3, que establece que es competencia exclusiva de los Jueces y Tribunales el juzgar y hacer ejecutar lo juzgado. 
gama de medios de los que puede disponer el juez para cumplir con la misión encomendada por la Constitución y por la nueva ley.

\section{ANTECEDENTES JURISPRUDENCIALES}

Ya algunas STC anteriores habían apuntado en esta dirección, pero sin llegar a establecer con la rotundidad que lo hace esta STC la embargabilidad de esta clase de bienes de la Administración. Entre otras destacan la STC 67/1984, de 7 de junio ${ }^{7}$. Alli se disponía:

"Cuando se incumple esta obligación de ejecutar la sentencia $-y$ de colaborar con los jueces en el plazo legalmente establecido-, el tribunal sentenciador, con audiencia de las partes, adoptará las medidas que considere procedentes para el cumplimiento de lo mandado; corresponde al Tribunal mencionado decidir cuáles son estas medidas, pero, desde la perspectiva constitucional que ahora interesa, debe señalarse que corresponde exclusivamente al mismo hacer "ejecutar lo juzgado" de acuerdo con las leyes y requerir las colaboraciones que estime precisas, por lo que ha de entenderse que tales medidas no pueden quedar limitadas por la falta de ejercicio de la competencia, en el plazo legalmente previsto, por la Administración autora del acto o disposición, en orden a la ejecución de la sentencia; en consecuencia, el juez puede aplicar las medidas previstas en la Ley de Enjuiciamiento Civil, de aplicación supletoria, entre las cuales puede ordenar que se haga lo mandado a costa del obligado (art. 924 de la Ley de Enjuiciamiento Civil)... requerir a tal efecto la colaboración que estime oportuna de otros entes públicos o personas privadas, en especial del Estado, pues la sentencia o la resolución de los jueces y tribunales emanan de un poder del Estado, y todos los poderes del Estado - en su sentido integral, es decir, comprendiendo las Comunidades Autónomas - tienen el deber de colaboración.»

De esta sentencia cabía deducir que las referencias a la aplicación supletoria del artículo $924^{8}$ y relacionado con éste, el $921^{9}$ de la Ley de Enjuiciamiento Civil, podían abrir, aunque de manera velada, la posibilidad de que los jueces dictaran providencias de embargo contra los bienes patrimoniales de la Administración. El T.C. sostenía que el derecho a la

\footnotetext{
7 Vid. un comentario a esta Sentencia en José Ignacio Morillo-Velarde PéreZ, «¿Es procedente el embargo de los bienes de la Administración en ejecución forzosa de sentencia condenatoria recaída en recurso contencioso-administrativo?», en REDA, n. ${ }^{\circ} 43$, julio-septiembre 1984, pp. 585-591.

${ }^{8}$ «Si el condenado a hacer alguna cosa no cumpliere con lo que se le ordene para la ejecución de la sentencia dentro del plazo que el juez al efecto le señale, se hará a su costa, y si por ser personalísima el hecho no pudiera verificarse en esta forma, se entenderá que opta por el resarcimiento de perjuicios. Si se hubiere fijado en la sentencia la importancia de éstos para el caso de inejecución, se procederá a lo que respecto del cumplimiento de la sentencia en que hay condena de cantidad líquida se previene en el artículo 921.»

9 «Si la sentencia condenare al pago de cantidad determinada y líquida, se procederá siempre, y sin necesidad de previo requerimiento personal al condenado al embargo de sus bienes en la forma y por el orden prevenido para el juicio ejecutivo...»
} 
ejecución de la sentencia no podía ser lesionado por un incumplimiento de la Administración.

También en una línea similar se habían pronunciado otras dos sentencias anteriores. La primera, la STC 32/1982, establecía que el principio de legalidad presupuestaria no podía suponer que se dejara sin contenido un derecho que la Constitución reconoce y garantiza y que, en ningún caso, este principio «puede justificar que la Administración posponga la ejecución de las Sentencias más allá del tiempo necesario para obtener, actuando con la diligencia debida, las consignaciones presupuestarias».

Asimismo, la STC 26/1983 establece que «Los privilegios que protegen a la Administración no la sitúan fuera del ordenamiento jurídico, ni la eximen de cumplir lo mandado en los fallos judiciales, ni priva a los jueces y tribunales de medios eficaces para obligar a los titulares de los órganos administrativos a llevar a cabo las actuaciones necesarias para ello».

De la misma manera, cierta jurisprudencia ordinaria se había mostrado favorable a la embargabilidad de los bienes patrimoniales de los entes locales. Así, entre otros, el Auto de la Audiencia Provincial de Zamora (Sala de lo civil) de 9 de mayo de 1997, que, sin poner en duda la constitucionalidad del artículo 154.2 de la LHL, entendía que la interpretación más adecuada, desde la Constitución, de tal precepto y en concreto de su cláusula «y bienes en general», era entender como inembargables únicamente los comunales y los bienes afectos a un uso o servicio público, pero no los patrimoniales que no lo estuvieran ${ }^{10}$. En esa misma línea el Auto

10 «Suponer para todos los bienes referidos un bloque monolítico invulnerable y no accesible a la realización del embargo, supondria desconocer el trazado de la $\mathrm{CE}$ en la que debe verse la tradicional distinción de bienes de patrimonio indispensable, bienes demaniales y bienes del patrimonio disponible, los cuales son susceptibles de ejecución, ya que de la lectura del artículo 132 no puede obtenerse otra conclusión que la siguiente: sólo la afectación de hecho y real y efectiva de los bienes al uso o at servicio público impide el embargo, de tal manera que si un bien concreto y determinado de la Administración municipal no goza del beneficio específico de la inembargabilidad (bienes comunales, bienes de dominio público), ese bien, a partir de la Constitución, es embargable y enajenable en pública subasta, no pudiendo tener la Administración respecto de los bienes patrimoniales una posición diversa y dominante de irritante desigualdad diversa a la de cualquier otro deudor. Por el contrario, el sentido de la prohibición general de embargo sólo debe entenderse cuando el ordenamiento retira de la esfera de agresión ejecutiva de los acreedores de la Administración aquellos bienes destinados a la especifica satisfacción de fines e intereses que se colocan por encima del derecho de crédito: el uso o el servicio público, en el caso de los bienes demaniales; el aprovechamiento común de los vecinos, en el caso de los comunales; y por ello fuera de esos supuestos acotados constitucionalmente no puede verse la impenetrabilidad del embargo para bienes que no se encuentren definidos por la afectación de hecho y real y efectiva que los adjetive como invulnerables para el embargo. Resulta de esta manera compatible la garantía en el pago de las deudas municipales activando los mecanismos de pago a través de las autorizaciones de crédito correspondientes y la ejecución por la vía de apremio sobre sus bienes patrimoniales una vez definida la naturaleza de los mismos.» 
de la Audiencia Provincial de Córdoba (Sala de lo civil) de 12 de febrero de 1997. Ya, antes también, la Sentencia de 4-7-1996 de la Audiencia provincial de Córdoba. Sala de lo civil. Sección $3 .^{\text {a) }}$ decía:

«... Procede hacer frente a la cuestión más espinosa que se plantea en la presente litis y que consiste en determinar si cabe o no embargar bienes patrimoniales y propios de las entidades locales... la resolución judicial que determine obligaciones a cargo de la Administración no habilita para iniciar la vía de apremio contra ésta, dictando providencia de embargo, sino que ha de ejecutarse siguiendo las previsiones legales a tal fin... El problema surge cuando la Administración adopta una postura de desidia ante la resolución judicial y no da cumplimiento a las previsiones legales administrativas para su ejecución, ya que en tal caso surge un enfrentamiento entre el derecho fundamental de tutela judicial efectiva del litigante y el de legalidad presupuestaria, debiendo evitar los Tribunales que aquella tutela sea inefectiva, como asi reconoce el Tribunal Constitucional... Será pues, en definitiva, cuando la Administración obstaculice el cumplimiento de las resoluciones judiciales cuando surja la posibilidad de embargarle bienes patrimoniales o propios, que parece ser el motivo por el que se embargó por el Juzgado bienes de esa naturaleza a una entidad local» ${ }^{11}$.

\section{INNOVADORA DOCTRINA DE LA STC 166/1998 ${ }^{12}$. EMBARGABILIDAD DE LOS BIENES PATRIMONIALES NO AFECTOS A UN USO O SERVICIO PÚBLICO}

Los hechos de los que se ocupa la STC 166/1998 son los siguientes: Por Sentencia de 28 de julio de 1988, el Juzgado de Primera Instancia n. ${ }^{\circ} 1$ de Burgos condenó al Ayuntamiento de esa misma localidad a pagar la cantidad de 51.567 .000 ptas., más intereses legales y costas a la empresa «Castellana de Publicidad Exterior, S. A.». Ante la falta de pago por parte del Ayuntamiento, la empresa solicita la ejecución de la Sentencia

11 Ratificando la inembargabilidad otra corriente jurisprudencial. En primer lugar, la STC 61/1984 de 16 de mayo. También la Sentencia de 28-11-1994, de la Sala de lo civil de la Audiencia Provincial de Asturias.

12 Esta Sentencia aqui analizada ha servido como base para la resolución de posteriores recursos de amparo. La STC 211/1998, de 27 de octubre de 1998 (BOE de 2 de diciembre de 1999), por ejemplo, establece que la doctrina de la STC 166/1998 es plenamente aplicable a un supuesto en que se produce una dilación indebida por el Ayuntamiento a la hora de llevar a cabo el cumplimiento voluntario de la Sentencia condenatoria, por el específico procedimiento administrativo, y que por tanto:

«... el derecho fundamental del acreedor a la ejecución de las resoluciones judiciales firmes (art. 24.1) impone a los órganos judiciales a instancia del particular adoptar las medidas oportunas para garantizar la efectividad de sus resoluciones, entre las que cabe el embargo ejecutivo, siempre que no recaiga sobre ninguno de los bienes o derechos..., que gozan de la prerrogativa de la inembargabilidad, y que sucintamente son los de dominio público, los comunales, los que integran la Hacienda del Ente local y los bienes patrimoniales materialmente afectados al sostenimiento de un servicio o uso público». 
pidiendo que se proceda al embargo de un solar del Ayuntamiento, que, por ser bien patrimonial, estaría sujeto a las normas de Derecho privado. El referido juzgado, ante esta petición, por providencia de 9 de noviembre de 1989 acuerda el embargo de los bienes patrimoniales de dicho Ayuntamiento, en cuantía suficiente para cubrir las cantidades a cuyo pago haya sido condenada la Administración. Ante el recurso de reposición contra la providencia, ésta es confirmada por Auto del Juzgado de Primera Instancia n. ${ }^{\circ} 1$ de Burgos, de 2 de diciembre de 1989. Contra ese Auto se interpuso recurso de apelación ante la Audiencia Provincial de Burgos, cuya Sala segunda plantea la cuestión de constitucionalidad, en relación con los apartados 2 y 3 del artículo 154 de la Ley 39/1988, de 28 de diciembre, reguladora de las Haciendas Locales, por posible vulneración de los artículos 24.1, 117 y 118 de la CE. La Audiencia considera que la tutela judicial efectiva debe llevar al cumplimiento del fallo judicial, en aras de evitar que la Sentencia firme se convierta para quien la obtuvo «en mera e ineficaz declaración formal», cumplimiento que se ve obstaculizado por la inembargabilidad general de los bienes de la Administración.

El Abogado del Estado entiende que debe ser desestimada la cuestión ya que la inembargabilidad, en este caso, está justificada y es proporcionada al fin constitucional que la legitima, dado que la traba o apoderamiento de los bienes públicos (incluidos los patrimoniales) supondría una violación del principio de legalidad presupuestaria, una perturbación de la estructura y ejecución del presupuesto y una obstrucción a la normal prestación de los servicios públicos. Entiende, también, que la regla de la inembargabilidad en general de los bienes públicos, ya sean patrimoniales o de dominio público, deriva directamente del principio de separación de poderes, en virtud del cual la Administración no puede verse perturbada para cumplir los intereses generales, y su patrimonio debe, por tanto, preservarse de medidas de traba o apoderamiento. Se trata, sin duda, de una lectura muy estricta de este principio la que hace el Abogado del Estado, una lectura muy al estilo francés postrevolucionario. El principio de la división de poderes ha sido suavizado en su radicalidad y no viene configurado en nuestro ordenamiento de una manera aislante, sino que los Tribunales tienen perfecta legitimidad constitucional para controlar la actuación de la Administración, salvo en aquellos casos en que de la Constitución quepa colegirlo así.

El análisis que realiza el T.C. tiene la misma estructura lógica que otras Sentencias anteriores que han tratado el tema de la inembargabilidad de grupos de bienes. Se procede a examinar si estas cláusulas de 
inembargabilidad son lesivas de algín bien jurídico protegido constitucionalmente, especialmente el derecho a obtener una efectiva tutela judicial (art. 24.1).

El Tribunal Constitucional ya en diferentes Sentencias ha hecho referencia a la compatibilidad de la inembargabilidad de ciertos bienes con el derecho a la tutela judicial efectiva. Y de esa confrontación ha extraído las siguientes consecuencias:

En primer lugar, tiene declarado el Tribunal Constitucional que el derecho a una tutela judicial efectiva abarca no solamente el derecho a obtener un pronunciamiento judicial sobre los litigios, sino también incluye el derecho a que los pronunciamientos judiciales sean ejecutados ${ }^{13}$. En este sentido, la STC 130/1986, de 12 de febrero:

"A este respecto, hay que tener en cuenta que, como viene repitiendo este TC, el derecho fundamental referido (a la tutela judicial efectiva) comprende el de obtener la ejecución de las resoluciones judiciales "en sus propios términos"...» ${ }^{14}$.

$Y$ en segundo lugar ha declarado en diferentes SSTC, entre otras la 159/1986, de 12 de diciembre, o la 23/1988, de 22 de febrero, que las limitaciones a los derechos fundamentales deben entenderse en sentido estricto:

"... tenerse en cuenta la doctrina de que los limites a los derechos fundamentales, en este caso del derecho fundamental a la ejecución de la sentencia que resulta

\footnotetext{
${ }^{13}$ En esta misma línea ChIOvenda: «L'azione può tendere all'attuazione della legge in piu modi: nella forma dell'accertamento mediante sentenza, nella forma di applicazione di misure cautelari, $e$ di misure esecutive». G. ChIovenda, Principi di diritto processuale civile (año 1905-06) Napoli, 1906, en p. 41.

14 Vid. también la STC 32/1982, de 7 de junio: «El derecho a la tutela jurisdiccional efectiva exige también que el fallo judicial se cumpla y que el recurrente sea repuesto en su derecho y compensado, en su caso, por el daño sufrido, ya que lo contrario sería convertir las decisiones judiciales y el reconocimiento de los derechos que ellas comportan en favor de alguna de las partes en meras declaraciones de intenciones»; la 26/1983, de 13 de abril: «El derecho a que se ejecuten los fallos judiciales sólo se satisface cuando el órgano judicial adopta las medidas oportunas para llevar a efecto esa ejecución, con independencia de cuál sea el momento en el que las dicta. Si esas medidas se adoptan, el derecho a la tutela judicial efectiva se habrá satisfecho...»; la 54/1983, de 16 de febrero; la 61/1984, de 16 de mayo: «La tutela de los derechos e intereses legítimos, que consagra el artículo 24 de la Constitución comprende... el derecho a que la Sentencia, que eventualmente haya puesto fin al proceso, se cumpla en sus propios términos, pues sólo de esta manera el derecho al proceso se hace real y efectivo, ya que si fuera de otro modo, el derecho no pasaría de ser una entidad ilusorian; la 106/1985, de 7 de octubre; la 151/1985, de 6 de marzo; la 169/1993, de 27 de mayo; la 206/1993, de 22 de junio: «Ahora bien, este derecho fundamental (24.1) no se satisface con una mera declaración judicial, desprovista de sustancia práctica, sino que necesita de su realización y, por tanto, la tutela, en cuanto efectiva por exigencia constitucional expresa, ha de llegar hasta el cumplimiento forzoso, si preciso fuere, de los pronunciamientos judiciales, donde se exterioriza la potestad de juzgar.»
} 
de la limitación de la inembargabilidad, han de interpretarse con criterio restrictivo y en el sentido más favorable a la eficacia y a la existencia del derecho.» (En la misma línea las SSTC 113/1989 de 22 de junio de 1989, la 138/1989 y la 140/1989, ambas de 20 de julio.)

El TC tiene sentada la doctrina ${ }^{15}$ de que el establecimiento por ley de la inembargabilidad de un tipo de bienes no vulnera por sí mismo el artículo 24.1 CE, si esa inembargabilidad se dispone en virtud de una justificación razonable y proporcionada, que precisa fines constitucionalmente legítimos ${ }^{16}$.

La clave del análisis es comprobar si los límites a la embargabilidad del artículo 154.2 LRHL responden a razonables finalidades de protección de valores bienes e intereses constitucionalmente relevantes y si la restricción al proceso normal de ejecución de sentencias guarda la debida proporción con esas finalidades.

En esta sentencia los límites de la confrontación, entre los diferentes bienes constitucionalmente protegidos, los traza el Tribunal en los siguientes términos. Si el mecanismo del artículo 154.4. de la LRHL ${ }^{17}$ se manifiesta suficiente para garantizar el efectivo cumplimiento de las resoluciones judiciales, en ese caso debe entenderse que no hay vulneración del derecho a la tutela judicial efectiva. Por tanto, la violación de este derecho fundamental sólo puede devenir si ese mecanismo habilitado por la Ley es insuficiente para garantizar la efectiva ejecución de las sentencias ${ }^{18}$. Si es insuficiente para garantizar la ejecución de las sentencias se estará produciendo una restricción desproporcionada y por tanto huérfana de cobertura constitucional. Tras este análisis, llega a la conclu-

${ }^{15}$ En esta línea la STC 158/1993, de 6 de mayo, sobre la inembargabilidad de ciertas pensiones.

16 También en relación con el artículo 14, el Tribunal ha entendido que éste se vulnera cuando no existe una justificación razonable y proporcionada que persiga fines constitucionalmente legítimos. Vid. las SSTC 54/1983, la 151/1985 o la 158/1993, de 6 de mayo. Vid., por su claridad, la STC 169/1993, de 27 de mayo, que establece: «Por lo que se refiere al principio constitucional de igualdad, cabe recordar que no serán conciliables con la Constitución las reglas especiales de inembargabilidad que carezcan de un fundamento o fin racional o que, aun teniéndolo, incurran en falta manifiesta de proporcionalidad.»

${ }^{17}$ Artículo que establece que ante una condena de pago a la Administración, ésta lo hará en la forma y con los límites del respectivo presupuesto, o si fuese necesario un crédito extraordinario o un suplemento de crédito, éste deberá solicitarse en los tres meses siguientes al día de la notificación de la resolución judicial.

18 Vid. Andrés De la Oliva SaNtos, «Notas sobre la ejecución de sentencias en el proceso administrativo", Doc. Ad., pp. 75-111 y en concreto 107-111, sobre las dificultades tradicionalmente existentes en el procedimiento administrativo para hacer efectivo el pago de la cantidad a que ha sido condenada la Administración. 
sión de que el régimen general de pago establecido en el artículo 154.4 de la LHL no garantiza que la entidad deudora cumpla con el mandato judicial, y que por tanto cabe la posibilidad de que la Administración posponga o difiera la ejecución de la sentencia dejando insatisfecho el crédito del particular. Por ello la inembargabilidad establecida en el 154.2, al extenderse a los bienes en general de la Hacienda Local y comprender los bienes patrimoniales no afectados materialmente a un uso o servicio público, no puede considerarse razonable desde la perspectiva del derecho a la ejecución de resoluciones judiciales firmes que el artículo 24.1 reconoce y garantiza. Tal limitación, en relación al artículo 24.1 , no encuentra justificación ni en atención al principio de eficacia de la Administración, ni en atención a la necesaria continuidad en la prestación de los servicios públicos. Tampoco entiende el Tribunal que la restricción a la tutela judicial efectiva pueda considerarse como proporcionada dada la generalidad con que se ha configurado la limitación al derecho fundamental. Mantiene, sin embargo, que la restricción en relación a los bienes de dominio público está justificada dado que es un soporte material de dicha actividad $y$, por tanto, necesario para la efectiva realización de los intereses generales a que sirve la Administración, y de ahí que su inembargabilidad sí esté justificada por la eficacia de la actuación administrativa y la continuidad en la prestación de los servicios. Sin embargo, no cabe realizar las mismas consideraciones en relación a los bienes patrimoniales no afectados materialmente a la realización de un servicio público, pues la relevancia pública de estos bienes radica únicamente en su titularidad, pero no en atención ni a la actuación que a aquella corresponde llevar ni al ejercicio de concretas potestades administrativas.

Si los bienes patrimoniales o de propios de las entidades locales son objeto del tráfico jurídico privado y están sometidos al Derecho privado estamos ante bienes de propiedad privada cuyos titulares se hallan en igual posición jurídica, sin perjuicio de las normas administrativas que rigen la gestión, administración y disposición de los que pertenecen a un ente público. Y, por ello, si el patrimonio como conjunto de bienes presentes y futuros tiene por fin responder del cumplimiento de las obligaciones contraídas por su titular, cabe su embargo. Tampoco está justificada esta exclusión si lo contrastamos con la seguridad jurídica que necesariamente debe presidir el tráfico jurídico.

Por todo ello el Tribunal declara nulo el artículo 154.2 y permite, por tanto, la embargabilidad de los bienes patrimoniales de la Administración local que no se encuentren afectos a un uso o servicio público. Se excluye de esta posibilidad a los patrimoniales que se encuentren materialmente 
afectos a un uso o servicio público, los comunales, los demaniales y aquellos otros que están sujetos a una legislación especial, significativamente, los inmuebles afectos al patrimonio municipal del suelo, los montes vecinales en mano común, los bienes muebles de notable valor histórico, artístico, arqueológico, científico, técnico o cultural.

\section{REFLEXIONES AL HILO DE LA SENTENCIA}

No corren buenos tiempos para la Administración, a la nueva Ley de la Jurisdicción Contencioso-Administrativa, que facilita e incrementa la tutela cautelar frente a los actos de la Administración y atribuye a los órganos judiciales la potestad de ejecutar las sentencias, se añade ahora esta posibilidad de embargar sus bienes patrimoniales no adscritos a un uso o servicio público.

El TC con esta sentencia no hace sino dar un paso más allá en el camino iniciado por el legislador, ya que éste con la Ley 66/1997, de 30 de diciembre, de medidas fiscales, administrativas y de orden social, ha dado una nueva redacción al artículo $\mathbf{1 5 4 . 2}$ de la Ley Reguladora de las Haciendas Locales, manteniendo como regla general la inembargabilidad de los bienes patrimoniales de los entes locales, pero introduciendo la embargabilidad de éstos cuando sirven de garantía a obligaciones hipotecarias... ${ }^{19}$ Esta nueva excepción introducida no tenía justificación ${ }^{20}$ y el que un crédito con garantía hipotecaria pudiera ser satisfecho con un procedimiento sumario de ejecución forzosa y no pudiera ser así, si la obligación no iba acompañada de una garantía hipotecaria, a pesar de haber sido declarada por sentencia judicial firme, parecía claramente injustificado ${ }^{21}$.

\footnotetext{
$19 \mathrm{El}$ apartado $2 .^{\circ}$ en su nueva redacción queda así: «Los Tribunales, Jueces y autoridades administrativas no podrán despachar mandamientos de ejecución, ni dictar providencias de embargo contra los derechos, fondos, valores y bienes en general de la Hacienda Local ni exigir finanzas, depósitos y cauciones a las entidades locales, excepto cuando se trate de la ejecución de hipotecas sobre bienes patrimoniales inmuebles no afectados directamente a la prestación de servicios públicos.»

${ }^{20}$ En esta misma línea Miguel SáNCHEZ MoRÓN, Los bienes públicos. (Régimen juridico), Tecnos, Madrid, 1997, p. 72.

${ }^{21}$ Vid. un breve comentario a la Sentencia aqui examinada, al estudiar la hipoteca como garantía real de las obligaciones de los entes locales, en Luis MORELL OCAÑA, Curso de Derecho Administrativo, vol. I, Aranzadi, Pamplona, 1998, pp. 606-608.
} 


\section{4,1. Influencia del sistema italiano. La separación entre patrimonio disponible y patrimonio indisponible}

La Constitución en su artículo 132 establece dos regímenes diversos para los bienes de dominio público y los comunales, por un lado, y para los patrimoniales, por otro. Establece además esta doble regulación con una redacción paralela muy significativa.

En su apartado $1 .^{\circ}$ este artículo dispone la reserva de ley para establecer el régimen jurídico de los bienes de dominio público y los comunales y a continuación fija que este régimen debe estar basado en los principios de inalienabilidad ${ }^{22}$, imprescriptibilidad e inembargabilidad ${ }^{23}$, así como su desafectación ${ }^{24}$. Sin embargo, cuando en el apartado tercero regula los bienes patrimoniales, establece de la misma manera la reserva de ley para su regulación ${ }^{25}$, pero no añade, como hacía en el párrafo anterior, los tres principios que deben guiar la regulación ${ }^{26}$. Este mismo modo de redactar en la LRBRL en el párrafo $1 .^{\circ}$ del artículo 80 en relación a los bienes de dominio público y en el párrafo segundo relativo a los bienes patrimoniales ${ }^{27}$.

22 Vid. Manuel Francisco Clavero Arévalo, La inalienabilidad del dominio público, Instituto García Oviedo, Sevilla, 1958, pp. 11-84. Vid., también sobre la inalienabilidad, el trabajo, ya clásico, de Arnaldo De Vallés, «Inalienabilità del demanio pubblico», en Riv. Dir. Pub., 1914, II, pp. 413-419.

${ }^{23}$ Vid., sobre la inembargabilidad de los bienes afectos a un uso o servicio público, José Esteve PARDO, «Consideraciones sobre la afectación de bienes al servicio público a partir de las llamadas "afecciones a non domino"», RAP, n. ${ }^{\circ} 113$, mayo-agosto 1987, pp. 181-213 y en concreto en nota a p. 181. El autor caracteriza al embargo como una afectación de bienes para garantizar patrimonialmente el derecho del accionante y por tanto la imposibilidad de embargar los bienes afectos a un uso o servicio público se produce como consecuencia del conflicto que surgiria de la doble afectación de un único bien.

24 Vid. un particular análisis de las características del dominio público en José Luis GonzAlez-Berenguer UrRutia, «Sobre la crisis del concepto de dominio público», en $R A P$, n. ${ }^{\circ} 56$, mayo-agosto de 1968, pp. 191-220. El autor defiende la tesis de la vacuidad de estas características.

25 Vid. sobre la reserva de ley en materia de Patrimonio del Estado y del Patrimonio Nacional la STC 58/1982, de 27 de julio.

${ }^{26}$ También en diversas STC entre las que destacan la 58/1982, de 27 de julio, o la 85/1984, de 26 de julio, se estableció que el régimen de transferencia de los bienes del Estado a las Comunidades Autónomas era diferente y debía articularse a través de mecanismos también diferentes según se tratase de bienes patrimoniales cuya cesión gratuita se hacía de acuerdo a los artículos 74-79 de la Ley de Patrimonio del Estado, legislación que no era operativa para el caso de transferencias de bienes de dominio público.

27 Artículo 80. «l. Los bienes comunales y demás bienes de dominio público son inalienables, imprescriptibles y no están sujetos a tributo alguno.

2. Los bienes patrimoniales se rigen por su legislación específica y, en su defecto, por las normas de Derecho privado.» 
Se aprecia que el constituyente establece estos tres principios únicamente para los bienes de dominio público y no para los patrimoniales.

La inembargabilidad es, de hecho, el único de los tres principios que caracteriza a los bienes de dominio público que aún el legislador mantenía aplicable a los bienes patrimoniales ${ }^{28}$.

Con esta STC se separa definitivamente el régimen de los bienes de dominio público y los patrimoniales, ya que se permite la embargabilidad de los patrimoniales y se establece una subdivisión dentro de los bienes patrimoniales que separa a aquellos que no son embargables por su destino, de aquellos que sí lo son por no estar afectos a un destino público ${ }^{29}$.

Se equipara, con ello, la situación de nuestro país, significativamente con Italia, país en el que parece inspirarse la STC que analizamos. En Italia ${ }^{30}$ ha existido tradicionalmente la separación entre bienes de dominio público, bienes patrimoniales indisponibles y bienes patrimoniales disponibles. Esta distinción entre patrimonio disponible y patrimonio indisponible se instituye ya por el Reglamento general sobre la contabilidad general del Estado de 4 de mayo de 1885.

\footnotetext{
${ }^{28}$ Entre otros preceptos que recogen esta regla, el artículo 18 de la Ley de Patrimonio del Estado: «Ningún Tribunal podrá dictar providencia de embargo, ni despachar mandamientos de ejecución contra los bienes y derechos del Patrimonio del Estado, ni contra las rentas, frutos o productos del mismo, debiendo estarse a este respecto a lo que dispone la Ley de Administración y Contabilidad de la Hacienda Pública.» La referencia que este artículo hace a la Ley de Administración y Contabilidad de la Hacienda Pública hay que entenderla referida a los artículos 44 y ss. de la Ley General Presupuestaria. También el artículo 44 de la Ley General Presupuestaria: «1. Los Tribunales, Jueces y Autoridades administrativas, no podrán despachar mandamiento de ejecución ni dictar providencias de embargo contra los derechos, fondos, valores y bienes en general de la Hacienda Püblica.» También se establece de forma general la inembargabilidad de todos los bienes del Patrimonio Nacional en el artículo 6.2 de la Ley 23/1982 del Patrimonio Nacional que dispone: «Los bienes y derechos integrados en el Patrimonio Nacional serán inalienables, imprescriptibles e inembargables, gozarán del mismo régimen de exenciones tributarias que los bienes de dominio público del Estado y deberán ser inscritos en el Registro de la Propiedad como de titularidad estatal.» En este caso pudiera entenderse apropiada la referencia general ya que, como más adelante veremos, la propia STC aquí analizada entiende como constitucional esa inembargabilidad de los bienes del Patrimonio Nacional por estar afectos al uso o servicio del Rey y de la familia real.
}

\footnotetext{
${ }^{29}$ Se consideran, por tanto, no embargables los bienes patrimoniales adscritos a un uso o servicio público, desde el primer día, y por tanto no será necesario esperar a la afectación presunta recogida en el artículo 8.4.b) del RBEL.

30 Vid., sobre este tema en general, Salvatore Buscema, Patrimonio pubblico (Individuazione del patrimonio pubblico. Principi generali sulla struttura dei conti patrimoniali pubblici e relativa gestione), Giuffrè, Milán, 1976. Vincenzo Cerull Irelli, Corso di Diritto Amministrativo, 9 ed. Giappichelli, Turín, 1997, pp. 656-666. Vid. también Pietro VIRGA, Diritto Amministrativo, vol. I, 5. ${ }^{a}$ ed., Giuffrè, Milán, 1995, pp. 362-413. Vid. también Ignazio Scotro, Diritto Amministrativo, 2. ed., Giuffrè, Milán, 1993, pp. 160-166.
} 
Esta STC al establecer dos regímenes diferentes para los patrimoniales adscritos a un uso o servicio público (que equivaldrían a los patrimoniales disponibles según la doctrina italiana) y los no adscritos a ese uso o servicio público (que serían los patrimoniales disponibles) recoge esta misma distinción. Es posible el embargo de los bienes patrimoniales que no se encuentren afectos a un uso o servicio público, de la misma manera que sucede en Italia en relación con los bienes patrimoniales disponibles, que están sujetos a la ejecución por deudas contra la Administración, como ha establecido, entre otras, la Sent. Cass. de 21 de julio de 1981, n. ${ }^{\circ}$ 4.696. También allí la mayor parte del dinero se considera inembargable (Sent. Cass de 14 de enero de 1981, n. ${ }^{\circ} 323$ ). La situación en Francia, sin embargo, es la misma que existía en nuestro país antes de la STC que aquí se analiza ${ }^{31}$.

\subsection{Extensión de los efectos de la Sentencia al resto de las Administraciones públicas territoriales}

La situación y las características de los bienes patrimoniales de las diversas Administraciones públicas son las mismas $\mathrm{y}$, por ello, tanto las consideraciones como el pronunciamiento del Tribunal son perfectamente aplicables y deben serlo, a la Administración del Estado y a la de las Comunidades Autónomas. Carecería de justificación y de apoyo constitucional que se eliminara este privilegio únicamente en relación a las Haciendas Locales y no así en relación al resto de Administraciones territoriales. Como expresamente ha dicho el propio Tribunal, aunque en una situación inversa, en su STC 4/1981, de 2 de febrero:

\footnotetext{
${ }^{31}$ En la doctrina francesa, tradicionalmente se ha entendido que los bienes de la Administración son inembargables, en general, cualquiera que sea su calificación. Esta situación se arrastra desde el Código napoleónico en el que partiendo de una concepción subjetiva no se establecía la separación entre bienes públicos y privados de la Administración. En este sentido ya, vid. la tradicional formulación de este principio en Maurice HaURou, Précis de droit administratif et de droit public, Rec. Sirey, París, 1914, 8. ${ }^{\mathrm{a}}$ ed., pp. 892 y 911 . Hauriou mantiene que el fundamento de este privilegio es la imposibilidad de los acreedores de la Administración de disponer sobre los fines de la Administración, ya que la posibilidad de embargar los bienes de ésta supondría tanto como interrumpir la gestión de los servicios públicos de cuya ejecución está encargada. Vid. en la actualidad este principio en René Chapus, Droit Administratif Général, 9. ed., vol. II, Montchrestien, París, 1996, p. 391, cuando afirma que la inembargabilidad no es una característica propia de los bienes de dominio público sino que lo es de todos los bienes de las personas públicas incluidos los bienes patrimoniales. Vid. George Vedel, Droit Administratif, PUF, París, 1990, pp. 357-364. Vid. también en esa misma línea André De Laubadère; Jean Claude Venezia, Yves Gaudemet, Traité de Droit Administratif, vol. II, 2. ${ }^{a}$ ed., LGDJ, París, 1992, p. 314. Vid. un análisis de las tendencias en el sistema francés de bienes públicos en Javier BARCELONA LLOP, «Novedades en el régimen jurídico del dominio público en Francia», RAP, n. ${ }^{\circ} 137$, mayo-agosto 1995, pp. 549-576.
} 
«El principio de defensa del patrimonio está presente en la Constitución, cuyo articulo 132 se refiere a la administración, defensa y conservación del $\mathrm{Pa}$ trimonio Nacional y del Patrimonio del Estado, por lo que debe sostenerse que idéntico principio habrá que aplicar al patrimonio de las Corporaciones Locales.»

Los motivos que el Tribunal entiende que dan lugar a la inconstitucionalidad como son la seguridad del tráfico, la característica de bienes de propiedad privada de los bienes patrimoniales, la falta de justificación de la limitación al artículo 24.1 en atención al principio de eficacia de la Administración, no son únicamente referibles a los bienes patrimoniales de la Administración local sino en general a los bienes patrimoniales de todas las Administraciones territoriales.

Por lo tanto, esta declaración de inconstitucionalidad debería arrastrar como corolario la inconstitucionalidad de todos los preceptos legales y reglamentarios que en nuestra legislación establecen la inembargabilidad, en general, de los bienes patrimoniales de cualquier Administración.

\subsection{Situación del resto de los preceptos que consagran la inembargabilidad de los bienes patrimoniales de la Administración}

A pesar de que parece obvio que la declaración de inconstitucionalidad de este artículo 154.2 debe extenderse a todos esos preceptos, el problema que se plantea es si es necesaria la declaración expresa de inconstitucionalidad de esos preceptos o si, como propone GARCÍA DE ENTERRIA ${ }^{32}$, no serán necesarias nuevas declaraciones de inconstitucionalidad de los preceptos que recogen la inembargabilidad de los bienes de las diferentes Administraciones públicas, y bastará con aplicar las leyes de acuerdo a la Constitución, ya que, como dispone el artículo 5 de la LOPJ, los jueces y tribunales deben aplicar las leyes de acuerdo a la interpretación que de los preceptos constitucionales haga el Tribunal Constitucional. Esta segunda solución parece la más acertada en relación a todos aquellos preceptos que de manera general consagran la inembargabilidad de los bienes de las Administraciones públicas y que, por tanto, no recogen una declaración expresa de la inembargabilidad de los bienes patrimoniales.

En el supuesto que aquí se analiza cabe realizar la interpretación del precepto más acorde a la Constitución y así lo hace esta sentencia, y, por

32 Vid. Eduardo García de Enterría y Tomás Ramón Fernández, Curso de Derecho Administrativo, vol. Il, quinta edición, Madrid, 1998, p. 646. 
tanto, entender que cuando se habla de inembargabilidad en general de los bienes de las Administraciones se hace referencia únicamente a los de dominio público y a los patrimoniales que no se encuentren afectos a un uso o servicio público. Sin embargo, entiendo que sí debería obtenerse esa declaración expresa de inconstitucionalidad de todos aquellos preceptos que expresamente recojan la inembargabilidad de los bienes patrimoniales, ya que en ese caso no cabe una interpretación adecuada a la Constitución, sino que lo que existe es un precepto que vulnera los dictados constitucionales $\mathrm{y}$, por lo tanto, así deberá ser declarado por el único órgano competente para ello.

\subsection{Consideraciones finales}

En primer lugar, alguna reflexión debe hacerse sobre la no extensión, por parte de esta sentencia, de la posibilidad de embargo a los caudales públicos ${ }^{33}$. Hubiera parecido adecuado, siguiendo la propia doctrina del Tribunal Constitucional, llegar a la conclusión de la embargabilidad del dinero público. Si analizamos, según los parámetros de la sentencia y en general de la doctrina del Tribunal Constitucional en relación a la inembargabilidad de ciertos tipos de bienes, la limitación que se produce al derecho a la tutela judicial efectiva por esta imposibilidad de embargo de los caudales públicos, no encuentra justificación ni en atención al principio de eficacia de la Administración ni tampoco en atención al principio de la continuidad en la prestación de los servicios públicos. Y es así ya que la Administración puede recabar fondos simultáneamente al embargo acudiendo al crédito. Además, la limitación al derecho a la tutela judicial efectiva no es proporcionada, ya que para la Administración, como apuntábamos, es fácil recoger dinero a través de operaciones de crédito mientras que para los particulares la inembargabilidad de los caudales, si la Administración no dispone de bienes patrimoniales no afectos al servicio público, puede dar lugar la inejecución material de la sentencia.

En segundo lugar, y como consecuencia lógica de esta sentencia, parecería necesario someter a un nuevo examen diversos privilegios de los que dispone la Administración a la hora de la ejecución de las sentencias. Este es el caso del diferente y menor tipo aplicable a los intereses procesales devengados en favor del acreedor cuando resulta condenada la Administración del Estado, por resolución judicial, al pago de una cantidad líquida. El artículo 921 LEC establece que cuando la resolución con-

33 De esta opinión Garcla de EnTERria, en Eduardo Garcla de EnTERría y Tomás Ramón FERnÁNDEZ, Curso de Derecho Administrativo, vol. II, quinta edición, Madrid, 1998, p. 645. 
dene al pago de una cantidad líquida, ésta devengará en favor del acreedor un interés igual al del interés legal del dinero incrementado en dos puntos, sin embargo, en el apartado segundo de ese mismo precepto se recoge la especialidad referente a la Hacienda Pública que en relación con el artículo 36.2 la Ley General Presupuestaria da lugar a un interés igual al legal del dinero sin incremento de los dos puntos. A este privilegio que, en la actualidad, opera únicamente en favor de la Administración del Estado y no así en relación a las Administraciones locales y autonómicas, tal y como ha reiterado en una línea homogénea el Tribunal Supremo ${ }^{34}$ cabe realizar dos críticas. La primera radica en que carece de fundamento que tal privilegio opere únicamente en favor de la Administración del Estado y no así en favor del resto de las Administraciones territoriales. Y en segundo lugar se trata de un privilegio injustificado de la Administración, a la que en un supuesto de incumplimiento exactamente igual al de un ciudadano se le exime de satisfacer ese recargo de dos puntos y se le intima, por tanto, con menos fuerza al cumplimiento temporáneo de las resoluciones judiciales, cuando si hay alguien que debe cumplir escrupulosamente los mandamientos judiciales, ese alguien debe ser la Administración, ya sea estatal, autonómica o local.

A raíz de esta sentencia es necesario un reexamen de la constitucionalidad de esta desigualdad, cuya justificación se nos escapa, y por tanto proceder a una revisión de la doctrina consagrada en la STC 206/1993, de

34 Vid. la STS de 3 de febrero 1996 (R. Ar. 889): «Como es bien sabido con carácter general desde el 4 de julio de 1984 en que entró en vigor la Ley 24/1984, de 29 junio, el quantum porcentual del interés legal del dinero es el básico del Banco de España determinado anualmente en los respectivos Presupuestos Generales del Estado. Esa cifra, incrementada en dos puntos, del modo expresado en el artículo 921.4. ${ }^{\circ}$ de la Ley de Enjuiciamiento Civil es la norma general, que comprende, a cualquier supuesto de condena a pago de cantidad líquida... La única excepción, pues, respecto al abono del plus de los dos puntos sobre el interés legal, la constituye la Hacienda Pública y solamente ella, sin que en dicho concepto estén comprendidas, a estos efectos, ni las Entidades u Organismos Locales ni las Comunidades Autónomas, puesto que la Hacienda Pública es una institución distinta de las diversas Haciendas Locales o de las Comunidades Autónomas, como lo pone de relieve el texto refundido de la Ley General Presupuestaria aprobado por el Real Decreto-Ley 1091/1988, de 23 septiembre, al establecer que la Hacienda Pública, a los efectos de esta Ley, está constituida por el conjunto de derechos y, obligaciones de contenido económico cuya titularidad corresponda al Estado o sus Organismos Autónomos.» Vid. también las SSTS de 5 de febrero de 1990 (R. Ar. 854); de 3 de abril de 1993 (R. Ar. 2.713); de 17 julio 1993 (R. Ar. 5.514); de 11 de febrero de 1995 (R. Ar. 2.061) y de 18 de abril 1995 (R. Ar. 3.407). O la de 13 de noviembre de 1997 (R. Ar. 7.953): «... es jurisprudencia constante de esta Sala que la excepción que efectúa el artículo 921 de la Ley de Enjuiciamiento Civil para la Hacienda Pública viene referida exclusivamente a la Administración del Estado, no siendo de aplicación cuando el obligado al pago resulte ser cualquier otra Administración..., estamos ante situaciones distintas, ya que la Hacienda Pública presenta diferencias en atención a su naturaleza subjetiva antológica así como peculiaridades, singularidades y características diferenciadoras con el resto de las Administraciones, de ahi que el legislador pueda prever un tratamiento jurídico diferenciado.» 
22 de junio ${ }^{35}$, que admitía tal desigualdad. Sentencia que, por otra parte, dio lugar a la formulación de dos votos particulares ${ }^{36}$.

Debe, por último, notarse la oportunidad perdida por la nueva Ley de la Jurisdicción Contencioso-Administrativa de haber introducido entre sus apartados esta posibilidad de embargo de los bienes patrimoniales no adscritos al uso o servicio público. Se podrá alegar que aún no se conocía el texto de la Sentencia, a lo que cabe responder que no era necesario esperar a pronunciamiento constitucional alguno, sino que las conclusiones a las que llega el máximo intérprete constitucional las podría haber alcanzado el legislativo con anterioridad.

35 Vid. también la STC 110/1996, de 24 de junio de 1996.

36 Vid. los votos particulares de don Vicente Gimeno Sendra y de don Álvaro Rodríguez Bereijo. 
